\title{
Maturação fisiológica e armazenamento pós-colheita de frutos e sementes de tomate cereja em transição agroecológica
}

\author{
Raimundo Gleidison Lima Rocha ${ }^{1 *}$, Maria Clarete Cardoso Ribeiro ${ }^{1}$, Fred Denilson Barbosa da Silva ${ }^{1}$
}

\begin{abstract}
RESUMO: A cultura do tomateiro é uma das mais importantes hortaliças cultivadas no Brasil, sendo sua utilização muito variada e com grande número de tipos de frutos existentes. O presente trabalho teve como objetivo verificar a influência dos estádios de maturação e armazenamento pós-colheita na qualidade fisiológica das sementes de tomate cereja da variedade Carolina. O trabalho foi realizado na fazenda experimental da Universidade da Integração Internacional da Lusofonia Afro-Brasileira (UNILAB), localizada em Piroás, distrito de Redenção-CE. Foi utilizado o delineamento inteiramente casualizado, em esquema fatorial 3x4 (três períodos de maturação: 40, 50 e 60 dias após a antese (DAA) e quatro períodos de armazenamento pós-colheita: 0, 5, 10, 15 dias). Foram avaliadas as variáveis: emergência de plântulas (\%); índice de velocidade de emergência (IVE); altura de plântulas; diâmetro de caule e comprimento de raiz. Sementes coletadas aos 40 DAA podem ser semeadas quando feito o armazenamento durante seis dias. Sementes coletadas aos 50 DAA não toleram períodos de armazenamento a partir dos 10 dias de armazenamento pós-colheita. Sementes coletadas aos 60 DAA não toleram períodos de armazenamento a partir dos 11 dias de armazenamento pós-colheita.
\end{abstract}

Palavras-chave: Lycopersicon esculentum, vigor, desenvolvimento de plântulas.

\section{Physiological maturation and post-harvest storage of cherry tomato fruits and seeds in agroecological transition}

\begin{abstract}
The tomato crop is one of the most important vegetables grown in Brazil, and its use is very varied and with a large number of existing types of fruit. The present work had as objective to verify the influence of the stages of maturation and post-harvest storage on the physiological quality of the cherry tomato seeds of the Carolina variety. The work was carried out at the experimental farm of the University of International Integration of Afro-Brazilian Lusophony (UNILAB), in Piroás, district of Redenção, Ceará State, Brazil. The completely randomized design was used in a $3 \times 4$ factorial scheme (three maturation periods: 40, 50 and 60 days after antesis (DAA) and four post-harvest storage periods: $0,5,10,15$ days). Seeds collected at 40 DAA can be sown when stored for six days. Seeds collected at 50 DAA do not tolerate storage periods from 10 days post-harvest storage. Seeds collected at 60 DAA do not tolerate storage periods from 11 days post-harvest storage.
\end{abstract}

Keywords: Lycopersicon esculentum, vigor, seedling development

\section{INTRODUÇÃO}

O tomateiro (Lycopersicon esculentum Mill.) vem da civilização Inca, no Peru Antigo da América do Sul, mas foi domesticado no México e introduzido na Europa em 1544. Mais tarde, disseminou-se da Europa para a Ásia meridional e oriental, África e Oriente Médio. Mais recentemente, distribuiu-se o tomate silvestre para outras partes da América do Sul e do México (NAIKA et al, 2006).

É uma das mais importantes hortaliças cultivadas no Brasil, sendo sua utilização muito variada e com grande número de tipos de frutos existentes (GUSMÃO et al., 2000). Dentre esses, encontram-se os tomates do tipo cereja, que vêm sendo comumente encontrados nos mercados, principalmente nos grandes centros, onde alcançam preços bastante atrativos aos produtores que se localizam próximo aos locais de comercialização (ROCHA, 2009).

Os fatores abióticos se constituem em um dos fatores primordiais para a obtenção significativa de mudas e produção de tomate. Temperaturas abaixo de $10{ }^{\circ} \mathrm{C}$ e acima de $36{ }^{\circ} \mathrm{C}$, iluminação diurnas inferiores a 12 horas, drenagem deficiente e excesso de nitrogênio provocam sérios prejuízos à cultura (ALVARENGA, 2004).

As sementes do tomateiro se desenvolvem a partir de óvulos fertilizados, que passam por transformações morfológicas, fisiológicas e funcionais até chegarem à maturidade fisiológica. Após atingir esse estágio, a planta cessa a translocação dos fotossintatos para o fruto. $\mathrm{Na}$ fase final da sua fase reprodutiva, suas sementes têm 
atingido o seu conteúdo máximo de matéria seca (CARVALHO; NAKAGAWA, 2000). Entretanto, este tipo de sementes pode, ou não, ter atingido valores máximos de germinação e vigor. Segundo Demir e Ellis (1992), em algumas espécies, o vigor máximo da semente é obtido simultaneamente ao ponto em que a matéria seca é máxima, enquanto que para outras pode ser verificado antes ou após o ponto máximo da matéria seca. Entretanto, quando as sementes atingem seu ponto máximo de maturação, inicia-se o processo de deterioração, reduzindo gradativamente a qualidade fisiológica da semente (CARVALHO; NAKAGAWA, 2000).

Em espécies de fruto carnoso, como as solanáceas, a maturação de frutos e sementes é continua após a colheita dos frutos. Esta característica das solanáceas permite que o produtor colha os frutos precocemente, submetendo-os a diferentes períodos de armazenamento pós-colheita que possibilitem que as sementes atinjam sua qualidade máxima. Em espécies que possuem o crescimento indeterminado, como o tomate, onde o florescimento é continuo e bastante desuniforme nos diferentes estádios de maturação durante a colheita, um menor número de colheita poderia ser realizado, colhendo os frutos em diferentes estádios de maturação, extraindo-se as sementes de frutos maduros, em seguida submetê-las a diferentes épocas de armazenamento pós-colheita.

Ao coletar frutos precocemente, o produtor teria como vantagens diminuir sua exposição às intempéries e aos ataques de pragas e microorganismos no campo (BARBEDO et al, 1994b).

Alguns estudos têm apresentado resultados significativos na qualidade fisiológica de sementes durante o desenvolvimento do fruto, sendo mais significativo em frutos que estão passando por uma transição de coloração do verde para vermelho (KWON; BRADFORD, 1987; DEMIR; ELLIS, 1992; VALDES; GRAY, 1998; PEREIRA, 2004). Nesse estudo a maior velocidade de germinação foi observada nas sementes extraídas de frutos colhidos maduros (completamente vermelhos) (VALDES; GRAY, 1998).

Em relação ao armazenamento pós-colheita, existem várias outras razões para seu estudo, considerando-se o custo final da produção, um menor período de tempo, aperfeiçoar a produção e manter contínua a demanda de mercado de sementes. Outro fator que ocasiona a desuniformidade na qualidade de sementes de hortaliças são asa condições ambientais, afetando a semente durante seu ciclo. Assim o armazenamento pode uniformizar a produção de sementes para dependendo da cultura (GEORGE, 1985).
No tomate, a maturação das sementes após a retirada do fruto da planta se torna uma vantagem por reduzir o número de colheitas. A retirada precoce dos frutos tem como outra vantagem a diminuição da exposição dos frutos às intempéries climáticas e aos ataques de pragas e doenças no campo (BARBEDO et al., 1994), levando à redução da qualidade das sementes.

Poucos estudos têm sido conduzidos com o fruto do tomate, relacionando a maturação dos frutos com a maturação das sementes. Em outras hortaliças como berinjela, pepino, pimentão e outras esses estudos já estão mais consolidados. Em função disso, conduziu-se esse estudo com o objetivo de verificar o desempenho de tomate cereja durante o amadurecimento dos frutos e armazenamento póscolheita de frutos e sementes.

\section{MATERIAL E MÉTODOS}

A condução da cultura até a colheita foi realizada na fazenda da Universidade da Integração Internacional da Lusofonia Afro-BrasileiraUNILAB, localizada em Piroás distrito de Redenção-CE. O armazenamento pós-colheita dos frutos foi em um ambiente com temperatura de 27 a $30{ }^{\circ} \mathrm{C}$, acondicionados em recipientes de plásticos, abertos e as análises de vigor no campus da Liberdade-UNILAB. Foram feitas sementeiras de jornal e preenchidas com a mistura de areia lavada e húmus de minhoca na proporção de 2:1.

Aos 42 dias após a semeadura, as mudas de tomate cereja atingiram $15 \mathrm{~cm}$ de altura, fez-se o trasplantio das mudas para os canteiros conforme preconizam Vidigal et al. (2006). Porém antes de realizar o transplante foi feito o controle curativo com manipureira contra nematóide das galhas na proporção de 1:1, um litro de manipueira para um litro de água, segundo informações de Ponte et al. (1995). Esta solução foi aplicada nas covas, com um litro de matéria orgânica para um litro de manipueira, por cova. Após a aplicação, aguardou-se oito dias para fazer o transplante das mudas de tomate cereja.

Quando as plantas atingiram 30 centímetros realizou-se o tutoramernto em $\mathrm{V}$ invertido conforme metodologia de (FONTES et al. 2002).

A variedade trabalhada foi tomate cereja Carolina. Foi feita semanalmente a desbrota dos ramos axilares para proporcionar a distribuição mais eficiente dos fotossintatos para frutos, sendo muito funcional para facilitar a aeração e o controle fitossanitário durante o ciclo da cultura. As flores foram etiquetadas no dia de sua antese, por ocasião do pleno florescimento das plantas de tomate, que ocorreu aos 20 dias após o trasplantio. Foram feitas 
as marcações nas flores com linha vermelho, amarelo e azul, em 50 flores para cada cor. As colheitas foram realizadas aos 40,50 e 60 dias após a antese (DAA). Os frutos colhidos em cada época foram mantidos em repouso por $0,5,10$ e 15 dias. Após cada período de repouso, as sementes foram removidas dos frutos e bem lavadas em água corrente. Na sequência, as sementes foram secas sobre papel toalha e postas para germinar em condição ambiente.

As variáveis avaliadas foram: índice de velocidade de emergência (IVE) e porcentagem de emergência. $\mathrm{Na}$ última contagem, as demais variáveis analisadas foram: altura de plântulas em centímetros, comprimento de raiz em centímetros, com auxílio de régua graduada e diâmetro do caule em milímetros, aferido com o auxílio do paquímetro digital.

Para avaliar o índice de velocidade de emergência, contabilizou-se diariamente durante 15 dias o número de plântulas emergidas, sendo determinado de acordo com a fórmula proposta por Maguire (1962) onde: $\mathrm{IVE}=\mathrm{E} 1 / \mathrm{N} 1+\mathrm{E} 2 / \mathrm{N} 2+\ldots$ $\mathrm{En} / \mathrm{Nn}$ Onde: IVE = índice de velocidade de emergência. E1, E2,... En = número de plântulas normais computadas na primeira contagem, na segunda contagem e na última contagem. N1, N2,... $\mathrm{Nn}=$ número de dias da semeadura à primeira, segunda e última contagem.

Os resultados de emergência de plântulas obtidas aos 15 dias foram expressos em porcentagem e calculados de acordo com Labouriau e Valadares (1976), onde $\mathrm{E}=(\mathrm{N} / \mathrm{A}) \times 100$ em que: $\mathrm{E}$ emergência, $\mathrm{N}$ - número total de plântulas emergidas e A - número total de sementes colocadas para germinar.

O delineamento experimental adotado foi 0 inteiramente casualizado em esquema fatorial $(3 \mathrm{x} 4)$, constituído por três épocas de colheita 40, 50 e 60 (DAA) e quatro períodos de armazenamento póscolheita $0,5,10$ e 15 dias. Os dados obtidos foram submetidos à análise variância (ANOVA) teste de Tukey a $5 \%$ de probabilidade para dados qualitativos. Para os dados quantitativos foi aplicado a análise de regressão, utilizando o software ASSISTAT 7.7 beta (SILVA; Na última contagem, determinou-se AZEVEDO, 20002).

\section{RESULTADOS E DISCUSSÃO}

$\mathrm{Na}$ emergência houve decréscimo no vigor das sementes conforme os períodos de armazenamento pós-colheita (Figura 1). O melhor resultado foi verificado no armazenamento pós-colheita durante seis dias em frutos coletados aos 40 DAA e também em frutos coletados aos 50 DAA, porém, nesse, resultados significativos foram obtidos quando não houve armazenamento pós-colheita.

A colheita precoce dos frutos diminui os custos com mão de obra em manejo da cultura. Conforme relata Pereira (2004), os frutos de tomate colhidos em início de amadurecimento e armazenados até serem completamente maduros produzem sementes de melhor qualidade.

Esses resultados comprovam os resultados obtidos por Vidigal et al. (2006) em sementes de tomate extraídas de frutos com 40, 50 e 60 dias de idade e armazenadas por 4, 8 e 12 dias, onde o período de pós-colheita favoreceu a germinação. Valdes e Gray (1998), ao colherem frutos de tomate com diferentes idades, mas sem submetê-los ao armazenamento pós-colheita, observaram que o tempo médio de germinação das sementes diferiu significativamente entre os estádios de maturação do fruto, sendo maior nas sementes menos maduras e decrescendo com decorrer da maturação. Em geral, observa-se maior vigor para as sementes extraídas de frutos com idade de 40 e 50 DAA, logo após a colheita, não havendo necessidade de armazenamento para a melhoria do vigor, ao contrário do que foi constatado por Alvarenga et al. (1991).

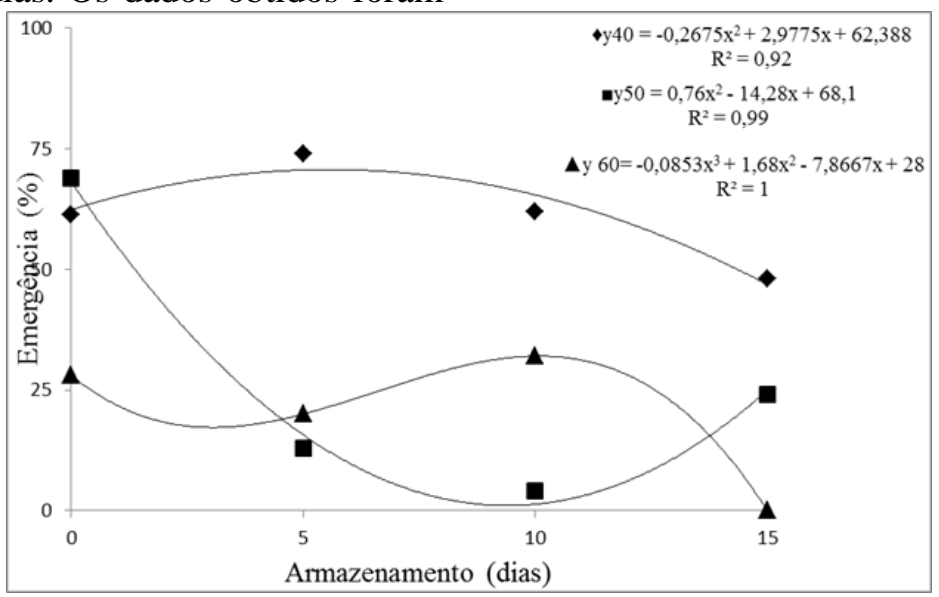

Figura 1. Emergência (\%) de plântulas de tomate cereja em função das épocas de maturação 50, 60, e 60 DAA e armazenamento pócolheita $0,5,10$ e 15 dias. 
Em relaçao ao índice de velocidade de emergência (IVE) (Figura 2), aos 40 DAA, observase efeito quadrático positivo, em que o vigor das sementes aumentou até os seis dias, decrescendo em seguida. Entretanto, ao coletar frutos aos 50 DAA, obteve-se ponto de minima aos 10 dias de armazenamento pós-colheita resultados de IVE, em relação aos demais períodos de armazenamento avaliados. Os menores resultados foram encontrados nos frutos colhidos aos 60 DAA em todas as épocas de pós-colheita ao serem avaliadas, com um comportamento cúbico (Figura 2).

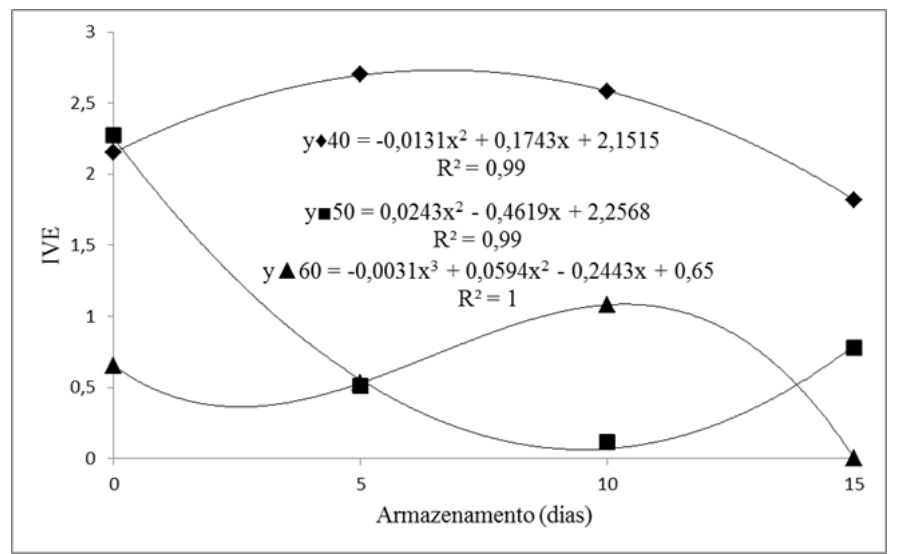

Figura 2. Índice de velocidade de emergência (IVE) em função das épocas de maturação 50, 60, e 60 DAA e armazenamento pócolheita $0,5,10$ e 15 dias.

Vidigal et al. (2006), avaliando a maturação fisiológica de tomate da variedade Kadá, grupo Santa Cruz, em três épocas (40, 50 e 60 DAA), e quatro períodos de armazenamento pós-colheita $(0$, 4,8 e 12 dias) obtiveram resultados semelhantes no IVE aos 50 DAA.

$\mathrm{Na}$ variável altura de plântulas sementes coletadas aos 40 e 50 DAA apresentaram decréscimo nos resultados a partir dos sete dias de armazenamento, nós demais dias houve um decréscimo significativo em relação às épocas de armazenamento (Figura 3).

$\mathrm{Na}$ altura de plantas aos 60 dias melhores valores foram encontrados quando foi feito $o$ armazenamento pós-colheita durante cinco dias (Figura 3).

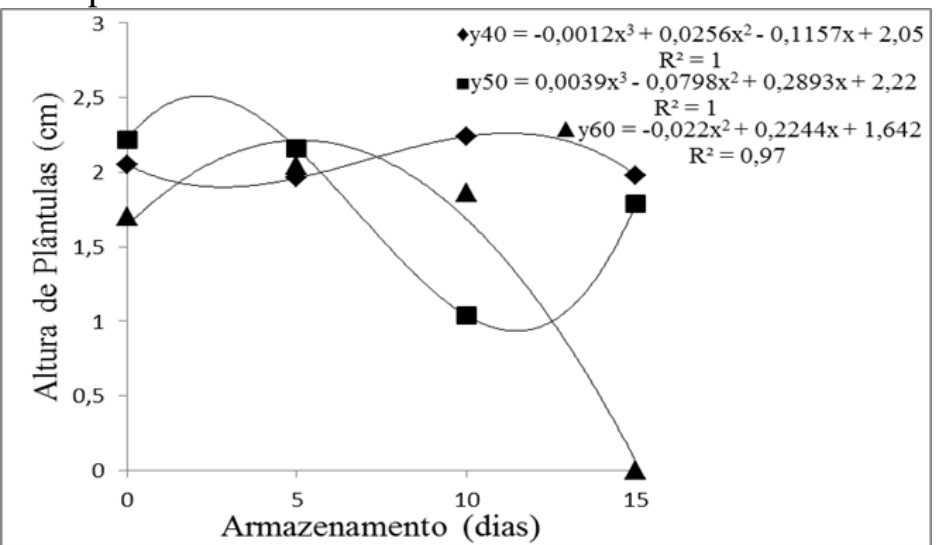

Figura 3. Altura de plântula em centímetros em função das épocas de maturação 50, 60, e 60 DAA e armazenamento pó-colheita 0,5 , 10 e 15 dias.

No comprimento de Raiz aos 40 DAA melhores resultados foram encontrados quando sementes formam armazenadas durante oito dias pós colheita (Figura 4).

As sementes coletadas aos 50 DAA o ponto de mínima obtido foi aos seis dias de armazenamento pós-colheita, continuando a decrescer (Figura 4).
No comprimento de raiz, melhores resultados foram encontrados quando sementes foram armazenadas durante quatro dias, quando coletadas aos 60 DAA. 


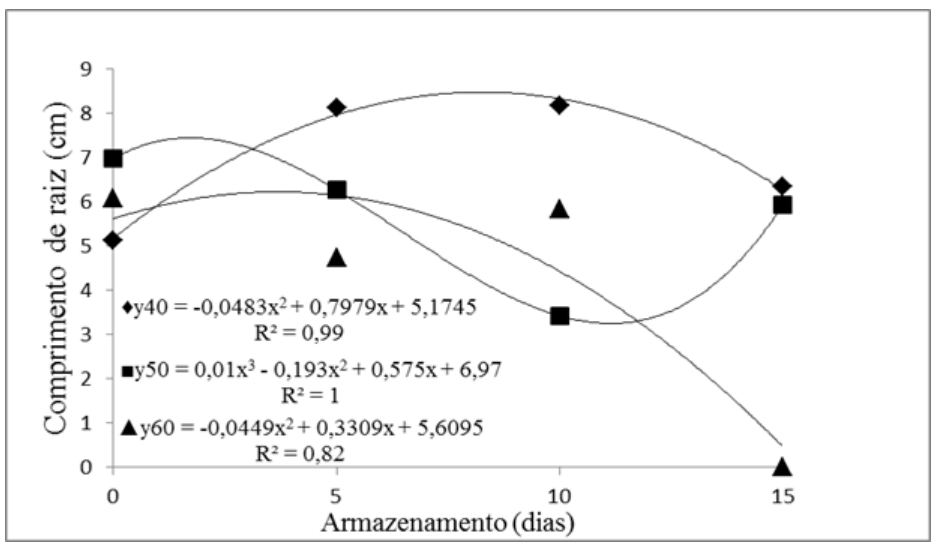

Figura 4 - Comprimento de raiz em centímetros em função das épocas de maturação 50, 60, e 60 DAA e armazenamento pó-colheita $0,5,10$ e 15 dias.

Quanto ao diâmetro do caule (Figrua 5), os melhores resultados foram obtidos em frutos coletados aos 50 DAA, não submetidos ao armazenamento das sementes. No tratamento 60 DAA, verifica-se acréscimo no diâmetro do caule até o quarto dia, reduzindo em seguida.

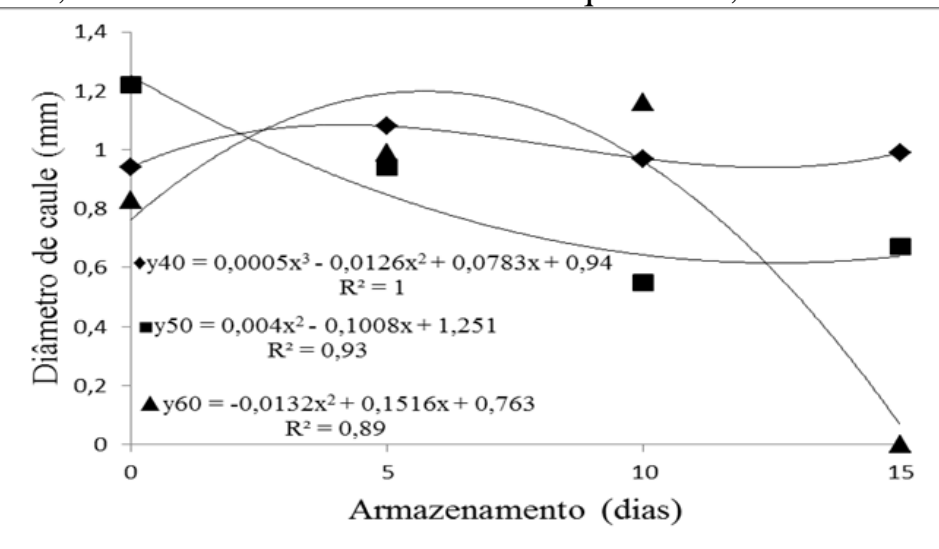

Figura 5 - Diâmetro do caule em função das épocas de maturação 50, 60, e 60 DAA e armazenamento pó-colheita 0, 5, 10 e 15 dias.

Após serem analisadas todas as variáveis, notouse que os frutos de tomate cereja demostraram diferenças em seu comportamento de vigor tanto nas épocas de maturação quanto nos períodos de armazenamento pós-colheita. O decréscimo do vigor de frutos do tomate cereja, provavelmente deve ser devido ao fato das suas sementes serem recalcitrantes.

Segundo Farrentet et al. (1998), sementes recalcitrantes, diferentemente das ortodoxas, não possuem a fase de desidratação, havendo um decréscimo na desidratação durante o estado de maturação fisiológico e diferentes dias de armazenamento pós-colheita, sendo os principais fatores que contribuíram para a perda de umidade das sementes. Assim, explica-se a queda de vigor em todas as variáveis analisadas das sementes do tomate cereja.

\section{CONCLUSÃO}

Sementes coletadas aos 40 DAA podem ser semeadas quando feito o armazenamento durante seis dias.

Sementes coletadas aos 50 DAA não toleram períodos de armazenamento a partir dos 10 dias de armazenamento pós-colheita.
Sementes coletadas aos 60 DAA não toleram períodos de armazenamento a partir dos 11 dias de armazenamento pós-colheita.

\section{AGRADECIMENTOS}

Os autores agradecem à UNILAB/PIBIC/CNPq pela concessão da bolsa de Iniciação Científica ao primeiro autor; assim como ao grupo de Tecnologia de sementes e produção de mudas e ao Laboratório de tecnologia de sementes, pelo apoio durante a execução do trabalho.

\section{REFERÊNCIAS}

ALVARENGA, E. M.; SILVA, R. F.; ARAÚJO, E. F.; CARDOSO, A. A. Influência da idade e armazenamento pós-colheita dos frutos na qualidade de sementes de melancia. Horticultura Brasileira, Brasília, v.2, n.2, p.58, 1984.

ALVARENGA, E. M.; SILVA, R. F.; ARAÚJO, E. F.; LEIRO, L. S. Maturação fisiológica de sementes de abóbora italiana. Revista Brasileira de Sementes, Brasília, v.13, n.2, p.147-150, 1991.

ALVARENGA, M. A. R. Tomate, produção em campo aberto, em casa-de-vegetação e em hidroponia: 
origem, botânica e descrição da planta. Lavras/MG: UFLA, 2004. 18p.

BARBEDO, C. J.; NAKAGAWA, J.; BARBEDO, A. S. C.; ZANIN, A. C. W. Influência da idade e do período de repouso pós-colheita de frutos de pepino cv, Rubi na qualidade fisiológica de sementes. Horticultura Brasileira, Brasília, v.12, n.2, p.14-18, 1994 b.

DEMIR, I.; ELLIS, R. H. Changes in seed quality during seed development and maturation in tomato. Seed Science Research, Wallingford, v.2, n.2, p.81-87, 1992.

FARRANT, J. M.; PAMMENTER, N. W.; BERJAK, P. Recalcitrance: a current assessment.

Seed Science and Technology, Zurich, v.16, p.155-166, 1988.

FONTES, P. C. R.; SILVA, D. J. H. Produção de Tomate de mesa. Viçosa - Minas Gerais, Editora Aprenda Fácil, 2002.

GEORGE, R. A. T. Vegetable seed production. New York: Longman, 1985. 318p.

GUSMÃO S.; PÁDUA J. G; GUSMÃO MTA de; BRAZ LT. 2000a. Efeito da densidade de plantio e forma de tutoramento na produção de tomateiro tipo "cereja" em Jaboticabal-SP. Horticultura Brasileira 18: 572-573.

KWON, O. S.; BRADFORD, K. J. Tomato seed development and quality as influenced by preharvest treatment with ethephon. HortScience, Alexandria, v.22, n.3, p.588-591, 1987.

LABOURIAU, L.G; VALADARES M.E.B. On the germination of seeds of Calotropis procera (Ait) Ait. $\mathrm{f}$. Anais da Academia Brasileira de Ciências, v.48, n.2, p.236-284.1976.

MAGUIRE, J. D. Speed of germination aid in selection and evaluation for seedling emergence and vigor. Crop Science, Madison, v. 2, n. 2, p. 176-177, 1962. Disponível em:

ttps://www.google.com.br/url?sa=t\&rct=j\&q=\&esrc=s\&s ource $=$ web $\& c d=1 \&$ cad $=$ rja $\&$ uact $=8 \&$ ved $=0$ ahUKEwiUk 9_68YPVAhWMVT4KHUX5BhwQFgglMAA\&url=http $\% 3 \mathrm{~A} \% 2 \mathrm{~F} \% 2 \mathrm{Fwww}$.cpao.embrapa.br\%2Fcds\%2Fmilhosa frinha2013\%2FPDF\%2F49.pdf\&usg=AFQjCNHu8pSjm WUHAauB7FEfv6Z5z5FBog> Acesso em: 12 de jun. 2017.

NAIKA, S.; JEUDE, J. V. L.; GOFFAU, M.; HILMI, M.; VAN DAM, B. A cultura do tomate: produção, processamento e comercialização. Fundação Agromisa e CTA, Wageningen, 2006. 06 p.

PONTE, J. J.; FRANCO, A.; SILVEIRA FILHO, J. Dosagem de manipueira para tratamentos de linhas de cultivo de solo infestado de nematoides. Nematologia brasileira, Vol. 19. 1995.
PEREIRA, F. P. Produção e qualidade de sementes de tomate em função do estádio de maturação do fruto e da ordem de frutificação na planta. 2004. 101p. Dissertação (Mestrado em Fitotecnia) - Universidade Federal de Viçosa, Viçosa, MG, 2004.

SILVA, F. A. S.; AZEVEDO, C. A. V. Versão do programa computacional Assistat para o sistema operacional Windows. Revista Brasileira de Produtos Agroindustriais, Campina Grande, v.4, n.1, p71-78, 2002.

ROCHA, M. Q. Crescimento, fenologia e rendimento do tomateiro cereja em cultivo hidropônico. 2009. $129 \mathrm{f}$. Dissertação (Mestrado em Sistemas de Produção Agrícola Familiar) - Universidade Federal de Pelotas, Pelotas, 2009.

VALDES, V. M.; GRAY, D. The influence of stage of fruit maturation on seed quality in tomato (Lycopersicon lycopersicum (L.) Karsten). Seed Science and Technology, Zürich, v.26, n.2, p.309-318, 1998.

VIDIGAL, D. S.; DIAS, D. C. F. S.; NAVEIRA, D. S.P .C; ROCHA, F. B.; BHERING, M. C . Qualidade fisiológica de sementes de tomate em função da idade e do armazenamento pós-colheita dos frutos. Revista Brasileira de Sementes, vol. 28, n 3, p.87-93, 2006.

VALDES, V. M.; GRAY, D. The influence of stage of fruit maturation on seed quality in tomato (Lycopersicon lycopersicum (L.) Karsten). Seed Science and Technology, Zürich, v.26, n.2, p.309-318, 1998. 